\title{
Lo normal y lo nombrado: una aproximación teórica al Derecho Público en Colombia *
}

\section{The normal and the named: A theoretical approach to Public Law in Colombia}

\author{
Marla Alejandra Motta Chavarro \\ Abogada, personera en el municipio de \\ Acevedo (Huila), Colombia \\ alejandramottach@gmail.com \\ Juan Sebastián Martínez Tovar \\ Antropólogo de la Universidad Nacional de \\ Colombia, Colombia \\ jsmartinezt@unal.edu.co
}

Recibido: 01/10/2018 Aprobado: 13/12/2018

DOI: $10.25054 / 16576799.2640$

\section{RESUMEN}

En esta investigación consideramos al derecho como una experiencia subjetiva es decir como un campo en el que diferentes actores despliegan estrategias para intervenir en su construcción. La pregunta crucial y punto de partida es, ¿cómo concebir el derecho?

Para responder, se ha dividido el trabajo en tres partes; primero, se hace un recorrido por diferentes conceptos del derecho, desde las ciencias jurídicas; como segundo, aunque se continúa con la reconstrucción del mismo concepto, su análisis se despliega desde un enfoque no jurídico, a través de pensadores ajenos al derecho; en la tercera y última parte, se expone qué se entiende por derecho público en esta investigación, relacionando los conceptos estudiados en los dos primeros apartados, y enlazándolos con el aparato teórico de Michel Foucault; es decir adoptando una postura analítica desde la biopolítica.

Finalmente, entendemos que el derecho público es un espacio de batalla, donde varias concepciones de lo normal se enfrentan por el monopolio de nombrar el derecho a la vida para una población. En este escenario se deslizan, además, los derechos sexuales y los derechos reproductivos, pues junto al derecho a la salud, disponen una forma-de-vida jurídica, acorde a la dignidad humana.

\section{PALABRAS CLAVE}

Derecho Público; Concepto; Derecho a la Vida; Derechos Sexuales; Derechos Reproductivos; Derecho a la Salud; Campo Jurídico; Población; Dignidad Humana.

*Artículo de investigación 


\section{ABSTRACT}

In this research we consider the law as a subjective experience that is, as a field in which different actors deploy strategies to intervene in its construction. The crucial question and starting point is, how to conceive the law? To answer this question, the work has been divided into three parts; first, a journey is made through different concepts of law, from the legal sciences; second, although the reconstruction of the same concept continues, its analysis is deployed from a non-legal approach, through thinkers outside the law; the third and last part sets out what is meant by public law in this research, relating the concepts studied in the first two sections, and linking them with the theoretical apparatus of Michel Foucault; In other words, adopting an analytical posture from biopolitics. Finally, we understand that public law is a space where different actors and multiple strategies intervene, facing the monopoly of naming the right to life for a population. In this scenario, sexual rights and reproductive rights are also slipping, because together with the right to health, they have a legal way of life, according to human dignity.

\section{KEYWORDS}

Public Law; Concept; Right to Life; Sexual Rights; Reproductive Rights; Right to Health; Legal Field; Human Dignity.

\section{INTRODUCCIÓN}

No existe una única concepción del derecho; al contrario, se presenta una pluralidad tan rica de "sistemas jurídicos, prácticas jurídicas y formas de convivencia regladas, sin orden jerárquico ni sometimiento racional de unos a otros" (Ariza, 2015 , p. 166), que resulta imposible reducirlo a un concepto total, definitivo y eterno. Por lo demás, si existe una pluralidad jurídica, no diferentes son las formas de resistir, conformarse u oponerse. Ewick y Silbey (2001), retomando a Foucault, afirman que la diversidad de conciencias jurídicas y sus resistencias, "están distribuidas de manera irregular; los puntos, los nudos o los centros de resistencia están dispersos en el tiempo y el espacio en densidades variables" (p. 269). Ante esta complejidad, surge la pregunta crucial y punto de partida de este artículo: ¿cómo concebir el derecho?

Para responder de la forma más clara posible, el contenido de este artículo está dividido en tres partes; cada apartado responde a una pregunta, así: 1) ¿Cómo se concibe al derecho, desde algunas teorías del mismo derecho?; 2) ¿Cómo se percibe al derecho desde otras disciplinas, fuera del campo jurídico?; 3) ¿Qué es el derecho público para esta investigación?
Así, el primer acápite, inicia con un breve recorrido a través de algunos doctrinantes jurídicos, pasando revista

por sus percepciones del derecho. Luego, se hace una exposición del mismo concepto desde Colombia, es decir desde la forma que la Constitución Política de 1991 consagró para el Estado. Finalmente, se muestra el enfoque jurídico que Hernando Valencia Villa, abogado colombiano y exprocurador delegado para los derechos humanos, propone en su texto Cartas de batalla.

El segundo apartado de este artículo, aunque continúa con la reconstrucción del mismo concepto, se hace desde un enfoque no jurídico. Así, este acápite empieza con una propuesta para el derecho, desde Marx; luego se hace un acercamiento a Michel Foucault, explorando cómo desde sus teorías puede entenderse el campo jurídico. Además se pasa revista por Walter Benjamin, Pierre Bourdieu y Georges Canguilhem $^{1}$, rastreando el mismo concepto.

Como tercer y último apartado, se expone la forma en que se entiende para esta investigación el derecho público. Para hacerlo, se enlazan las diferentes concepciones expuestas en los dos anteriores apartados, tejiendo además algunas teorías como la biopolítica de Foucault, a través de Beatriz Preciado y Giorgio Agamben ${ }^{2}$.

1 Valga la pena aclarar, que ninguno de estos autores es jurista.

2 Igual que los anteriores, ni Agamben ni Preciado son abogados. Por el contrario, ambos se dedican al estudio de la biopolítica, desde la gestión de la vida, o nuda vida, y desde la sexualidad -su resistencia contra-sexual-, respectivamente. 
También se rescata del mismo autor, el concepto analítico de "dispositivo", pertinente para comprender la propuesta de este artículo para el derecho. Por lo mismo, en este apartado se define también qué se entenderá por derecho a la vida, derechos sexuales y derechos reproductivos, principales categorías de análisis en el desarrollo de este trabajo. Como último en este tercer apartado, se expondrá por qué el derecho puede concebirse como una experiencia subjetiva.

Tras exponer cómo es el desarrollo de este artículo, es de resaltar por qué es importante realizar un ejercicio así para la disciplina del derecho. Es de saberse que antes que pretender soluciones definitivas o respuestas totales que abarquen sin duda la realidad, lo que se propone este trabajo es problematizar el campo jurídico. Más que una propuesta nueva, resulta interesante en cuanto nos obliga a cuestionar y dudar aquello tenido como incuestionable en el campo jurídico. Es decir, se considera primordial la capacidad de problematizar, antes que una propuesta nueva. Sin aspirar a soluciones finales, se formulan preguntas sobre el derecho, como lo propone Georges Canguilhem (1971): "nos importa menos proporcionar una solución provisional que mostrar que un problema merece ser planteado" (p. 135). Además, poner en cuestión al derecho, "nos obliga a tomar posición, abandonando el cómodo relativismo o las respuestas preconcebidas" (Borrero, 2006, p. 8). Finalmente, el ejercicio de problematizar el derecho, evidencia la pluralidad jurídica, su ser inacabado y en proceso, dinámico, por lo que al tiempo, permite reclamar "la posibilidad de intervenir en esta construcción" (Preciado, 2002, p. 76). Así, lo más interesante de este ejercicio, es ejercer como derecho, la participación en la construcción del derecho.

\section{EN NOMBRE DEL DERECHO, O DE CÓMO NOMBRARSE ASÍ}

\subsection{Breve aclaración sobre la historia del derecho}

No existe una única concepción del derecho; al contrario, se presenta una pluralidad tan rica de "sistemas jurídicos, prácticas jurídicas y formas de convivencia regladas, sin orden jerárquico ni sometimiento racional de unos a otros" (Ariza, 2015 , p. 166), que resulta imposible reducir el derecho a un concepto total, definitivo y eterno. Por lo demás, si existe una pluralidad jurídica, no diferentes son las formas de resistir, conformarse $\mathrm{u}$ oponerse. Ewick y Silbey (2001), retomando a
Foucault, afirman que la diversidad de conciencias jurídicas y sus resistencias, “están distribuidas de manera irregular; los puntos, los nudos o los centros de resistencia están dispersos en el tiempo y el espacio en densidades variables" (p. 269).

Es decir que, contrario a un concepto claro y determinado para el derecho, existe una pluralidad jurídica, como sus resistencias y la conciencia jurídica -formas en que el derecho adquiere sentido-:

(...) el término "conciencia jurídica" es usado por los científicos sociales para referirse a las maneras como la gente da sentido al derecho y a las instituciones jurídicas, esto es, a las concepciones que dan sentido a las experiencias y acciones de la gente (Ewick y Silbey, 2001, p. 273).

Ante esta complejidad, surge la pregunta crucial y punto de partida de este artículo: ¿cómo concebir el derecho?

Cuando Rodolfo Arango (2016) expone su concepción del derecho en "Una mirada histórica a los derechos", hace primero un sondeo a través de diferentes autores sobre el mismo concepto. Así, pasa revista por John Locke afirmando que para éste "los hombres tendrían derechos naturales a la libertad y a la propiedad, no pudiendo el orden político desconocerlos" (p. 21); igual por Bentham, quien suponía que los derechos humanos eran "disparates en zancos", contrarios a la economía. Posteriormente, se detiene en Marx y afirma que para éste el derecho es un instrumento de dominación burguesa. Continúa con el concepto de Kelsen y el iuspositivismo, asegurando que para éste el derecho es un fenómeno cultural, resultado de unas normas positivas que se crean en sociedad.

Para Alf Ross y su realismo filosófico, el cual no es muy diferente de Kelsen -según Arango (2016)-, se propone que el derecho es semejante a la magia o la religión, en cuanto las normas jurídicas deben ser creídas como ciertas para que puedan funcionar: "el carácter mágico-religioso del derecho, [es] muy importante para la obediencia a la ley y para la aceptación normativa" (p. 23). Y tras sondear a otros autores, como Robert Alexy o Rorty y los pragmatistas, que concebían el derecho como "creaciones culturales u objetos intencionales", afirma el mismo Arango (2016) su propio concepto del derecho: "posiciones normativas de un sujeto (individual o colectivo) para las cuales es posible dar razones válidas y suficientes, cuyo no reconocimiento injustificado le ocasiona un daño 
inminente a su titular” (p. 33).

Arango expone diversos conceptos de derecho, hace evidente la pluralidad jurídica y al final plantea la suya; así se revela que desde la misma disciplina del derecho, múltiples conceptos existen, lo que hace imposible un registro único. Por lo anterior, a continuación se expone lo que es el derecho como práctica oficial en Colombia; se analiza la concepción del derecho desde el Estado Social de Derecho (desde ahora ESD), consagrado en la Constitución Política de 1991.

\subsection{Estado y Derecho}

Atender al derecho a partir de la concepción que del Estado se tiene en la Constitución Política de 1991, es interesante en cuanto no todo concepto jurídico resulta tener fuerza vinculante; es decir, no toda concepción del derecho funciona como deber ni crea obligaciones para los ciudadanos. Así exista una pluralidad jurídica, no toda postura es práctica ni posible en Colombia. Por lo mismo, las fuentes principales a continuación analizar, son la Constitución y la jurisprudencia Constitucional, en cuanto "entre la Constitución y la Corte Constitucional, cuando ésta interpreta aquélla, no puede interponerse ni una hoja de papel", como se aseguró en la sentencias C-113 de 1993 y C-131 del mismo año, con ponencia del Magistrado Alejandro Martínez Caballero.

Por lo demás, para reforzar los argumentos constitucionales, también resulta importante atender a la doctrina; así, en el texto de Arango (2016), "El concepto de goce efectivo de derechos", se expone lo siguiente:

El lenguaje para referirse a los derechos humanos y fundamentales ha variado con el tiempo. Se ha pasado de un lenguaje de derechos de libertad, negativos o de abstención, donde las obligaciones del Estado se centraban fundamentalmente en abstenerse de violar los derechos y protegerlos contra agresiones de terceros, a un lenguaje más abarcador que el de los derechos de libertad, y que incluye además de estos los derechos a la organización, al procedimiento y a prestaciones públicas positivas (...) actuar positivamente para garantizar el goce o disfrute efectivo de los derechos a las personas, especialmente a aquellas que requieren de una protección especial (pp. 110-111).
Se evidencia en la cita, la relación del derecho con el Estado, así como su transformación. De una relación de choque y abstención, de contrariedades y negativas, se pasa a una relación productiva y activa, donde los derechos accionan al Estado con prestaciones como los servicios públicos.

Este cambio entre el derecho y el Estado significó también el origen del ESD, como en Colombia ocurre desde la Carta Superior del 91. Borrero (2006), con relación al tema, expone:

La cláusula del Estado social de derecho (C.P. art. 1), tiene el poder jurídico de movilizar a los órganos públicos en el sentido de concretar, en cada momento histórico, un modo de vida público y comunitario que ofrezca a las personas las condiciones materiales adecuadas para gozar de una igual libertad. En este orden de ideas, tras este objetivo la Constitución consagra derechos sociales, económicos y culturales; asigna competencias al legislador; establece como deber del Estado asegurar la prestación eficiente de los servicios públicos a todos los habitantes del territorio nacional; amplía el ámbito de responsabilidades de la administración en punto a la gestión, inspección y vigilancia de los servicios y prestaciones a cargo del Estado; abre un claro espacio de participación a los usuarios y beneficiarios de los servicios y prestaciones estatales (pp. 165166).

Como se ve, los derechos positivos de prestaciones que ponen en acción al Estado tienen el nombre de Derechos Económicos, Sociales y Culturales (desde ahora DESC). Nos preguntamos ahora, con relación a la doctrina del ESD y los DESC, ¿qué exponen las fuentes enunciadas como principales? Una sentencia que, sin lugar a dudas, es hito por muchos aspectos de Ciro Angarita, la sentencia T406 de 1992, comienza desarrollando extensamente qué es el ESD, consagrado en el Artículo 1 de la Constitución de 1991. Lo primero que asegura es que "el término "social", ahora agregado a la clásica fórmula del Estado de Derecho, no debe ser entendido como una simple muletilla retórica que proporciona un elegante toque de filantropía a la idea tradicional del derecho y del Estado".

Como segundo punto, tras dejar en claro que no se trata de simple retórica, dice el Magistrado Ponente que la incidencia del ESD puede describirse desde un enfoque cuantitativo, es decir "bajo el tema del Estado bienestar", o desde lo cualitativo, es decir 
"bajo el tema del Estado constitucional democrático". Para el Estado bienestar, dice la misma sentencia, se trata del "Estado que garantiza estándares mínimos de salario, alimentación, salud, habitación, educación, asegurados para todos los ciudadanos bajo la idea de derecho y no simplemente de caridad". Para el Estado constitucional democrático, dice la misma providencia:

[se trata de una] respuesta jurídico-política derivada de la actividad intervencionista del Estado. Dicha respuesta está fundada en nuevos valores-derechos consagrados por la segunda y tercera generación de derechos humanos y se manifiesta institucionalmente a través de la creación de mecanismos de democracia participativa, de control político y jurídico en el ejercicio del poder y sobre todo, a través de la consagración de un catálogo de principios y de derechos fundamentales que inspiran toda la interpretación y el funcionamiento de la organización política (CConst, T-406/1992, M.P. C. Angarita).

Así, frente al objetivo de este artículo, lo que realiza el ESD es, según lo afirma el mismo Ciro Angarita, un cambio en la concepción jurídica, pues con el paso del Estado de Derecho (desde ahora ED) al ESD, el texto sacramental de la Ley (como el Principio de Legalidad), al igual que la Seguridad Jurídica, pierden su importancia para refundarse en la justicia material, la equidad que otorga a cada ciudadano una igual libertad. Resumiendo qué es el ESD, Germán Alfonso López Daza (2017), recordando a García-Pelayo, expone sus principales características:

1) Velar por la creación y el mantenimiento de condiciones de vida decentes para el conjunto de los ciudadanos, asegurando la prestación social y los servicios de asistencia a las personas más desvalidas.

2) Igualdad de oportunidades para el acceso de todos los individuos a la educación.

3) Mantener una estabilidad económica gracias a una intervención y control por parte del Estado.

4) Protección social a los más desfavorecidos (López-Daza, 2017, p.187).

Una última discusión ante estos DESC: podría juzgarse por lo anterior expuesto que los derechos sociales, de segunda generación, no tienen relación alguna con los derechos de primera generación o libertades negativas. Lo anterior podría considerarse como un error. Así como hay una continuidad, aunque con transformaciones, entre el ESD y el ED, las diferentes generaciones de derechos también se interconectan. Así, aunque los derechos de libertad son pensados como cartas para los individuos, cual si fueran derechos privados (y sin lugar a dudas lo son), vale la pena aclarar que antes son derechos públicos. Bajo estas condiciones, se considera en Colombia que la propiedad privada (art. 58 de la Carta Superior) no es posible sin unas mínimas condiciones económicas que permitan el acceso de todos los ciudadanos al mercado; por lo demás, el mismo artículo Superior dispone que "la propiedad es una función social que implica obligaciones.

Como tal, le es inherente una función ecológica". Es decir, el derecho privado a la propiedad es público también. No diferente ocurre con la autonomía de las personas y el libre desarrollo de la personalidad (art. 16), donde no es posible decidir con entera libertad y privacidad una forma para vivir, cuando no hay un mínimo de educación, salud, habitación, alimentación, información y trabajo. Además, desde la constitucionalización del derecho (López-Daza, 2017), como ocurre en Colombia desde 1991, todo el sistema jurídico está atravesado por la Constitución; por lo mismo, cualquier derecho, sin importar su generación o contenido, si es sustancial o procesal, dogmático u orgánico, de libertad o prestación, se relaciona con la dignidad humana y es fundamental (López-Daza, 2017).

Para resumir, puede decirse que el derecho son cartas que sirven, tanto para poner al Estado en acción como para impedir su intromisión en la vida de los individuos, protegiendo la autonomía de cada uno de los ciudadanos. Es decir, que el derecho puede ser entendido como cartas necesarias para la formación de la dignidad humana, tanto para protegerle como para impulsarle: vela tanto las libertades individuales que impiden al Estado decidir por la vida de los ciudadanos (cosificándolos), al tiempo que adelanta prácticas, genera contextos y construye espacios para el desarrollo óptimo de la dignidad. Así y solo así, la dignidad es materialmente justa, libre e igual, en lugar de un decir que se desvanece en el aire o se pierde entre hojas viejas. 


\subsection{Otras cartas para el derecho: ¿batallas sin triunfo?}

La concepción del derecho que a continuación se expondrá, desde el mismo derecho, resulta interesante porque, aunque es propuesta por un jurista, se desliza entre otras disciplinas. Por lo demás, también es relevante que dicha teoría sea propuesta por un abogado colombiano, Hernando Valencia Villa (1987), en su libro Cartas de batalla.

Para empezar, cabe aclarar que esta concepción puede considerarse como una crítica a lo que normalmente se entiende por derecho:

Se trata de presentar una crítica de las filosofías legales desde el punto de vista de una noción estratégica o polemológica del derecho que se opone a la concepción consensual o funcional que campea por doquier. Mi visión del derecho como gramática de la guerra, sin embargo, no es un esquema rígido sino un dispositivo dinámico (pp. 30-31).

Asegurar que el derecho es un dispositivo, sin lugar a dudas, es la propuesta que se dispone en la tercera parte de este artículo, cuando se define qué concepción de derecho se acoge. Por lo demás, lo que propone este autor es una noción de derecho que critica aquellos conceptos que le consideran como un acuerdo social o una forma de organizar a la sociedad humana dispar. Es una idea de derecho que critica una forma preestablecida para vivir.

Quizá parezca una postura jurídica radical, no obstante la sentencia T-622 de 2016 dice que la "implementación del profuso catálogo de derechos de la Carta Política, constituye una caja de herramientas constitucional, [la cual] ha permitido que los derechos se ejerzan con algún grado de eficacia instrumental". Sea como sea, sí resulta interesante considerar el derecho como gramática de la guerra, en oposición a las muy repetidas y actuales teorías tradicionales que le consideran como normas consensuales o disposiciones que buscan el bienestar social o el ideal de la humanidad. La propuesta de Valencia (1987) es tratar al derecho como "gramática de la guerra"; es decir:

Puesto que lo que denominamos derecho no es una estructura externa impuesta a la dinámica social en nombre de uno u otro imperativo, acaso nuestro objeto de estudio esté constituido más bien por un tipo de práctica polivalente que une y separa a los individuos y a los grupos a la vez que traza en su movimiento el mapa de un combate, el plano de una campaña, la estrategia y las tácticas de una batalla perpetua: la de los seres humanos que luchan consigo mismos y unos contra otros por el reconocimiento y la supremacía (Valencia, 1987, p. 43).

En Cartas de batalla, Valencia (1987) considera a Michel Foucault como el precursor de "este novísimo modelo de análisis de lo jurídico" (p. 44). No obstante, simultáneamente aclara que las teorías de Foucault son contrarias a semejante concepción de derecho. Esta contraposición, se hace evidente en la crítica que desarrolla otro jurista, el peruano Fernando de Trazegnies:

(...) aparentemente, toda la riqueza de análisis de Foucault sobre el poder se detiene misteriosamente ante las murallas infranqueables de una concepción tradicional del derecho; el efecto corrosivo de la perspectiva que Foucault propone no logra disolver las estructuras rígidas de una idea de derecho anquilosada y mecánica (...) pareciera que el derecho es considerado únicamente bajo la forma de la Gran Represión impuesta desde la cumbre política del poder: el fenómeno jurídico constituiría así una forma binaria del poder administrada desde arriba, que reduce las situaciones al juego de lo lícito y lo ilícito, de la transgresión y el castigo (Valencia, 1987, p. 48).

Finalmente, Valencia (1987) expone su concepción del derecho, acorde al mismo jurista peruano, Trazegnies:

El derecho no es una "cosa" sino un "espacio" donde suceden cosas, no es una transcripción estática del gran poder sino un lugar donde se definen los poderes a través de múltiples escaramuzas (...) el derecho es la batalla misma, una batalla que no termina nunca (p. 48).

Como se mostró al inicio de este artículo, existe una pluralidad jurídica (Ariza, 2015); igualmente, múltiples son las resistencias en el derecho (Ewick y Silbey, 2001). Por lo tanto, no basta con evidenciar la pluralidad, es necesario analizar las formas en que esta multiplicidad se relaciona en un espacio estratégico, posicional y relacional. Las 
diferentes concepciones del derecho no son indiferentes entre sí, por el contrario, chocan y resisten, según posturas y cambios de intereses de una sociedad. Así nacen los mapas de combate y los planos de campaña que conforman la gramática de la guerra, el derecho como dispositivo, no una "cosa" sino un "espacio", donde las posturas y las resistencias de una sociedad se despliegan entre múltiples estrategias en conflicto.

\section{EL DERECHO DESDE AFUERA, O DE CÓMO HACERSE DOBLE}

\subsection{Unas manos para el derecho}

La historia para Marx (1974), entendida desde las condiciones reales de producción en una sociedad y no desde los imaginarios o las ideologías o los conceptos, es lo que reproduce al derecho. Igualmente, para Marx el derecho es una herramienta ideológica en manos de la burguesía para defender sus intereses de clase. En la misma línea, Pierre Bourdieu (2000) denomina a Marx como instrumentalista; es decir, "que comprende el derecho como un reflejo o un instrumento al servicio de los dominadores" (p. 155). Así, pareciera ser cierto que para Marx el derecho es un invento de la clase social moderna, dueña de los medios de producción, útil para legitimar sus intereses: el impulso de la economía liberal.

Palabras más, palabras menos, y de acuerdo a lo planteado por Bourdieu y Arango, el propio Marx (1974) expone en La ideología alemana lo que considera como derecho:

Y cuando la burguesía era ya lo suficientemente fuerte para que los príncipes tomaran bajo su protección sus intereses, con la mira de derrocar a la nobleza feudal por medio de la burguesía, comenzó en todos los países -como en Francia, durante el siglo XVI- el verdadero desarrollo del derecho (p. 73).

Pareciera que no hay duda con respecto al pensamiento de Marx, el derecho existe gracias al desarrollo y la protección de los intereses de la burguesía. Sin embargo, esto no resulta ser tan exacto; más acorde a Marx (1974), sería decir que el derecho es un producto histórico y, por lo mismo, condicionado por las relaciones reales de producción en que vive una sociedad. En otras palabras, antes que una utilidad burguesa, el derecho responde a las condiciones históricas de una sociedad. El propósito principal del filósofo alemán consistió en demostrar que el derecho ni era natural ni una gracia de Dios, como tampoco un problema conceptual o ideal; por el contrario, relacionó las normas jurídicas al trabajo y la producción, las manos que transforman la naturaleza entre conflictos, otorgándole, por demás, un carácter dinámico. No de otra forma puede entenderse la siguiente crítica:

Ya estamos acostumbrados a la idea de que las relaciones jurídicas se presenten, al igual que en otros casos, como el imperio del concepto del derecho, lo que le permite matar al derecho convirtiéndolo en un concepto y, por tanto, en lo sagrado (Marx, 1974, p. 372).

Efectivamente, para Marx el derecho se vuelve sagrado, muerto, cuando se le formula como un concepto. Y es precisamente contra esta muerte del campo jurídico que Marx reacciona. Lo mismo es decir que no hay una única forma de derecho o que resulta ser doble: por un lado se da como concepto -que le mata- y, por el otro, se vincula con las condiciones sociales de producción que le dinamizan -como la vida-. De este modo, pueden trabajarse "distintas formas de derecho" (Marx, 1974, p. 403); entonces el derecho no es unívoco y menos un instrumento en manos de los dominantes; por el contrario, es múltiple y acepta distintas formas en cuanto responde a una dinámica productiva, las condiciones reales de la historia donde los seres humanos luchan por el reconocimiento de sus intereses (Valencia, 1987).

\subsection{El cuerpo del derecho}

Tal cual se dijo antes, con Valencia (1987) y el jurista peruano Trazegnies, Michel Foucault alimentó una concepción del derecho "anquilosada y mecánica"; es decir, entendió la justicia como sanción, y al poder como la "Gran Represión”. Esto es verdad, no obstante -al igual que con Marx y el derecho como instrumento burgués para dominar-, no es tan exacta.

En Vigilar y castigar, Foucault (1975) inicia con dos cuadros bastante particulares; primero expone la decisión de una sentencia judicial -sobre el caso de Robert François Damiens, procesado por atentar contra la vida del Rey Luis XV-, donde el condenado debía realizar (¿o sufrir?) “pública retractación ante la puerta principal de la Iglesia de París" (Foucault, 1975, p. 11). Ese "retractarse" al que debía ser sometido Damiens no era un acto voluntario o libre, menos informado -como es lo conveniente desde un enfoque de derechos en la actualidad-; su retractación debía ser ante la Iglesia 
y bastante protocolizada, por lo que era necesario conducir al condenado como la sentencia disponía:

(...) en una carreta, desnudo, en camisa, con un hacha de cera encendida de dos libras de peso en la mano (...) en dicha carreta, [debía ser llevado y conducido] a la plaza de Grève, y sobre un cadalso que allí habrá sido levantado [deberán serle] atenaceadas las tetillas, brazos, muslos y pantorrillas, y su mano derecha, asido en ésta el cuchillo con que cometió dicho parricidio, quemada con fuego de azufre, y sobre las partes atenaceadas se le verterá plomo derretido, aceite hirviendo, pez resina ardiente, cera y azufre fundidos juntamente, y a continuación, su cuerpo estirado y desmembrado por cuatro caballos y sus miembros y tronco consumidos en el fuego, reducidos a cenizas y sus cenizas arrojadas al viento (Foucault, 1975, p.13).

La Gazzette d'Amsterdam, también citada por Foucault (1975), describe con más detalle cómo fue la operación para descuartizar al condenado y la razón de su largo suplicio: "los caballos que se utilizaban no estaban acostumbrados a tirar; de suerte que en lugar de cuatro, hubo que poner seis" (p. 13). La cantidad de caballos no fue suficiente para zafarle las piernas y los brazos, y como los animales se iban agotando y los dedos de Damiens seguían en su lugar junto a él, fue necesario "cortarle los nervios y romperle a hachazos las coyunturas" (p. 13). Por lo demás, "fue preciso cortar las carnes hasta casi el hueso; los caballos, tirando con todas sus fuerzas, se llevaron el brazo derecho primero, y el otro después" (p. 13); entonces el verdugo declaró al condenado muerto. No obstante, hubo quien luego le vio "agitarse, y la mandíbula inferior subir y bajar como si hablara" (p. 13). También se dijo que "incluso poco después que cuando levantaron el tronco del cuerpo para arrojarlo a la hoguera, estaba aún vivo" (p. 13). Finalmente concluye el relato de la forma más sincera y contundente: "en cumplimiento de la sentencia, todo quedó reducido a cenizas" (p. 13).

Posteriormente a este relato, Foucault expone doce (12) Artículos "para la Casa de jóvenes delincuentes de París”, donde según el Artículo 17:

La jornada de los presos comenzará a las seis de la mañana en invierno, y a las cinco en verano. El trabajo durará nueve horas diarias en toda estación. Se consagrarán dos horas al día a la enseñanza. El trabajo y la jornada terminarán a las nueve en invierno, y a las ocho en verano (Foucault, 1975 , p. 14).

Los otros Artículos disponen las actividades del día a día en "la Casa de jóvenes delincuentes" con minucia; hora por hora se diseña un quehacer: se organizan las horas de trabajo, alimentación y educación, como el momento de irse a dormir, Artículo 28 del mismo Reglamento:

\begin{abstract}
A las siete y media en verano, y a las ocho y media en invierno, los presos deben hallarse en sus celdas, después de lavarse las manos y de haber pasado la inspección de las ropas hecha en los patios. Al primer redoble de tambor, desnudarse, y al segundo, acostarse. Se cierran las puertas de las celdas y los vigilantes hacen la ronda por los corredores, para cerciorarse del orden y del silencio (p. 15).
\end{abstract}

Pareciera ser que los cuerpos ya no se destruyen sino que se forman y organizan en un tiempo rígido; de las horribles condenas que despedazan manos, piernas y cabezas, se pasa al ABC que enseña a trabajar -aprovechar el tiempo-. El mismo Foucault (1975) dice: "he aquí, pues, un suplicio y un empleo del tiempo (...) definen muy bien, cada uno, un estilo penal determinado" (p. 15). Nos preguntamos, entonces, ¿está presente el derecho en ambas formas de pena, tanto en el suplicio como en el reglamento? ¿Son ambos estilos penales, parte del derecho? Pertinente resulta rescatar ahora y para empezar, que entre los dos cuadros que se deslizan al iniciar Vigilar y castigar, el derecho puede percibirse como a continuación se evidenciará.

Entre ambos estilos penales no pasa ni un siglo y, sin embargo, marcan momentos históricos muy diferentes. Según Foucault (1975), la Casa para jóvenes delincuentes data empezando el Siglo XIX, momento en que se transforma la manera de castigar, acorde a los cambios sociales, económicos y políticos que se presentaban. Surge una nueva era de la justicia penal, nuevos valores y políticas ante el derecho a castigar, como teorías jurídicas sobre la economía de las sanciones o la creación de los códigos "modernos" (p. 15).

Estas reformas se dirigieron hacia una "humanización" de la pena y así desaparecieron los suplicios. En otras palabras, hacer el salto 
argumentativo desde Damiens a la Casa para jóvenes delincuentes, del suplicio al empleo del tiempo, no fue otra cosa que la humanización de las penas y el surgimiento de una nueva forma de castigar, donde "ha desaparecido el cuerpo supliciado, descuartizado, amputado, marcado simbólicamente en el rostro o en el hombro, expuesto vivo o muerto, ofrecido en espectáculo. Ha desaparecido el cuerpo como blanco mayor de la representación penal" (Foucault, 1975, p. 16).

Con la humanización de las penas, nada semejante al suplicio de Damiens puede aparecer, nada como "la poesía de Dante hecha leyes" (Rossi en Foucault, 1975, p. 40); tampoco para la humanización de la vida, concepción moderna del derecho junto a la dignidad. Es así como la vida -y la muerte- se enmarca en el sistema jurídico, gestionándose a partir de cálculos y reglamentos, contrario a cualquier exceso, como en el caso de Damiens.

\subsection{La magia del derecho: violencia doble}

El suplicio de Damiens y el Reglamento para la Casa de jóvenes delincuentes, recuerdan el ejercicio de la violencia, por lo que retomamos los planteamientos de Walter Benjamin y lo que el filósofo alemán entiende por derecho, porque "la tarea de una crítica de la violencia puede circunscribirse a la descripción de la relación de ésta respecto al derecho y a la justicia" (Benjamin, 1991, p. 23).

Según Benjamin, la violencia de la guerra no se ve entre las mutilaciones o la sangre que produce el campo de batalla, sino en la paz; la huelga es violencia precisamente porque no toma acciones de hecho como el incendio o el sabotaje, sino que dialoga. La policía es violencia no porque pueda golpear con el bolillo o inmovilizar a una persona, sino porque cumple con un derecho nuevo, como si fuese una disposición eterna y sagrada sobre la vida y la muerte. Es decir, la violencia en la huelga se da cuando ésta "puede implantar o modificar condiciones de derecho por más que le pese al sentido de la justicia" (Benjamin, 1991, p. 28). La violencia de la huelga se da, precisamente, porque no hay nada como una violencia que destruye las cosas, sino porque modifica lo que se concibe por derecho. Cuando una huelga cumple su objetivo y se dialoga, se pueden conceder nuevos derechos, puede el orden jurídico modificarse, y por lo mismo, es una violencia. Se reconfigura qué sí y qué no es derecho.
Igual la violencia en el derecho de guerra no se da tanto en el campo de batalla que mata y descuartiza, sino en la paz, capaz de modificar la forma en que el derecho se nombra, se divide y se distribuye:

La palabra "paz", correlativa de la palabra "guerra", incluye en su significado (distinto al de la "paz eterna" política y literal de Kant) un necesario sancionamiento a priori de cada victoria, independientemente de todas las otras relaciones de derecho. Y esta sanción consiste en que las nuevas circunstancias son reconocidas como nuevo "derecho" (Benjamin, 1998, p. 29).

Lograr que la huelga modifique qué es derecho, al igual que la paz, evita el sabotaje entre los trabajadores o el incendio de la fábrica, como los muertos y los heridos en combate. Conceder derechos impide la destrucción de los cuerpos y los bienes, calculando las necesidades y los deseos de una población, como la insatisfacción que puede acarrear una lucha o la guerra. En cada caso es una preocupación económica sobre cómo administrar las fuerzas sociales, anticipándose a cualquier eventualidad que pueda resultar en conflicto.

Violencia para Walter Benjamin (1991), entonces, es esa forma de ordenar el mundo jurídicamente, que dispone entre normas lo que sí y lo que no es derecho, qué es bien y mal, qué es legítimo y justo, qué es vida y muerte. Se dispone la vida, el pasado y el futuro, a través de la violencia que describe al derecho, "la utilización de violencia sobre vida y muerte refuerza más que cualquier otra de sus prácticas al derecho mismo" (p. 31). Para no olvidar, puesto que más adelante se retomará, disponer de la vida y de la muerte es un asunto fundamental que refuerza al derecho mismo.

Hasta aquí tenemos que la violencia del derecho es su propia transformación, como en la huelga y la paz, cuando se conceden nuevos derechos. No obstante, una vez modificada la concepción jurídica, se naturaliza como fundamental. Lo recién otorgado conjura al pasado y al futuro, haciéndose pasar como eterno, definido y necesario. Este movimiento de la violencia del derecho es primordial, en cuanto muestra su proceso doble, que no es diferente a su carácter. En palabras de Benjamin (1991):

La función de la violencia en el proceso de fundación de derecho es doble. Por una parte, la fundación de derecho tiene como 
fin ese derecho que, con la violencia como medio, aspira a implantar. No obstante, el derecho, una vez establecido, no renuncia a la violencia (p. 40).

El nuevo derecho transforma al derecho preestablecido, precisamente porque éste preestablecido también fue nuevo y el nuevo será luego preestablecido; es decir, cuando el recién fundado derecho se vuelve conservador, se cumple con el segundo momento de la violencia. La transformación impuesta se hace permanente, se naturaliza y se vela como objetiva, fundamental. Este doble movimiento del derecho es importante en cuanto lo nuevo será luego preestablecido, cuando otro nuevo aparezca. Y así sucesivamente se va modificando, entre lo nuevo y lo preestablecido. Por lo mismo, Benjamin (1991) dirá: "desechable es, empero, toda violencia mítica, la fundadora de derecho, la arbitraria. Desechable también es la conservadora de derecho, esa violencia administrada que le sirve" (p. 45). Es decir, constantemente se funda un nuevo derecho sobre sus propios escombros, y "funda un nuevo derechos sobre sus ruinas" (p. 44).

Este carácter doble que da Walter Benjamin al derecho, resulta interesante porque, al igual que con Marx -donde un producto de las relaciones reales de producción se vela de naturalidad fundamental, un concepto sagrado (muerto)-, relaciona lo que Pierre Bourdieu llama la fuerza del derecho. Es decir, el derecho resulta doble, según esta trinidad de autores. Para Bourdieu (2000) el derecho es un campo con reglas específicas y determinadas donde se disputa el monopolio del derecho a decir derecho. Se trata de un combate que debe practicarse a través de sus propias fórmulas, que se transforma según los actores y sus estrategias, renovándose con el paso del tiempo; muy semejante a lo que Benjamin entiende por violencia:

entrar en el juego, aceptar jugar el juego, ponerse en manos del derecho para reglar el conflicto, es aceptar tácitamente la adopción de un modo de expresión y de discusión que implica la renuncia a la violencia física y a las formas elementales de la violencia simbólica, como la injuria (Bourdieu, 2000, p. 186).

"Aceptar tácitamente" (las reglas que el derecho dispone para reglar conflictos, rechazar la violencia que descuartiza o la injuria, aceptar la paz y el diálogo como la huelga) cualquier cosa es cuestión de no dudar -no presenta cuestión-: el derecho es entonces un campo en el cual debe creerse. Solo puede concebirse el carácter doble del derecho, cuando se acepta como fundamental, regla del pasado y el futuro, natural y de siempre, por la vida y la muerte, lo que a cada instante es redefinido. No otra razón tiene Bourdieu (2000) para compararle con la magia:

La eficacia de todos los actos de magia social, de los que la sanción jurídica representa la forma canónica, no puede operar sino en la medida en que la fuerza propiamente simbólica de la legitimación, o mejor, de naturalización (lo natural siendo lo que no presenta cuestión acerca de su legitimidad) recubre y redobla la fuerza histórica inmanente que la autoridad y la autorización de esos actos refuerza o libera (p. 200).

La violencia fundamental se hace violencia conservadora y perpetua, lo nuevo se transforma en viejo, de ayer y mañana, se funda un nuevo derecho sobre sus propias ruinas, cuando él mismo es, también, escombros. En otro texto, Bourdieu (1991) lo dice mejor:

La fuerza específica del derecho es algo muy paradójico, casi impensable. Hay que volverse a Marcel Mauss y a su teoría de la magia. La magia sólo actúa en un campo, es decir, un espacio de creencia en cuyo interior están los agentes socializados de manera que piensen que el juego al que juegan merece ser jugado. La ficción jurídica no tiene nada de ficticio; y la ilusión, como dice Hegel, no es ilusoria. El derecho no es lo que dice ser, lo que cree ser, es decir, algo puro, completamente autónomo, etc. Pero el hecho de que se crea tal, y que logre hacerlo creer, contribuye a producir unos efectos sociales completamente reales; y a producirlos, ante todo, en quienes ejercen el derecho (p. 5).

El derecho adquiere su fuerza al creerse puro, autónomo, sagrado o por fuera de las relaciones sociales, cuando es justo lo contrario, ligado a la historia y sus conflictos, a las dinámicas de la economía, el trabajo y los problemas sociales; es magia para jugar, aunque se presente como fundamental y con reglas definidas, rígidas, naturales y universales. Es decir, el derecho vuelve a evidenciar -como se mostró con Walter Benjamin 
(1991)- su papel desechable, al considerar lo contingente como universal; un interés particular que impone el derecho a decir derecho, se vuelve inmediatamente eterno, conjurando el pasado y el futuro, la vida y la muerte, el bien y el mal para una población:

El trabajo jurídico tiene efectos múltiples. La codificación liga continuamente el presente al pasado al arrancar las normas a la contingencia de la ocasión particular, al fijarlas en una decisión ejemplar (una sentencia, por ejemplo), y hacerlo en una forma destinada a servir de modelo ella misma a decisiones ulteriores y que autoriza y favorece al mismo tiempo la lógica del precedente, fundamento del modo de pensar y de la acción propiamente jurídica. La codificación garantiza también que, salvo una revolución capaz de cuestionar los fundamentos mismos del orden jurídico, el futuro será la Imagen del pasado (Bourdieu, 2000, p. 208).

Resulta importante que el precedente o cualquier codificación jurídica garantice una "imagen" del futuro semejante al pasado, en cuanto Bourdieu asegura que el derecho es un campo donde se lucha por el monopolio a decir derecho, cuando este nombrar resulta ser más una visión, una división o distribución. Efectivamente, es punto central del pensamiento de Bourdieu (2000) concebir los nombres como imágenes y no como conceptos:

En esta lucha -en la que se enfrentan visiones del mundo diferentes, en ocasiones antagonistas, que pretenden imponer su reconocimiento en la medida de su autoridad y consecuentemente hacerse realidad- está en juego el monopolio del poder para imponer el principio universalmente reconocido del conocimiento del mundo social, el nomos como principio universal de visión y de división (nemo significa separar, dividir, distribuir), por consiguiente, como principio de distribución legítima (pp. 196-197).

El principio de distribución legítima que se da en la lucha por el monopolio a nombrar qué es el derecho, no es diferente a la violencia para Walter Benjamin, cuando éste logra determinar qué es la vida y qué es la muerte. Es decir, se universaliza o naturaliza lo que a unos actores les interesa y llaman derecho; o como Bourdieu (2000) lo explica, hay un "efecto de normalización". Se hace normal lo que no es sino una forma de nombrar y normativizar, ver y distribuir. Lo dice así el mismo autor:

Y uno se puede sorprender de que la reflexión sobre las relaciones entre lo normal y lo patológico conceda tan poco espacio al efecto propio del derecho: el derecho, instrumento de normalización por excelencia, en cuanto discurso intrínsecamente poderoso y dotado de los medios físicos para hacerse respetar, está en disposición de pasar, con el tiempo, del estado de ortodoxia, creencia explícitamente enunciada del deber ser, al estado de doxa, de adhesión inmediata a lo que se presupone, a lo normal, como culminación de la norma que queda abolida en cuanto a tal en su perfección (pp. 213-214).

Se normaliza lo normativo, una norma se vuelve normal y un invento se hace innato. Este doble movimiento del derecho se revela entre Marx -la producción se hace natural-, Benjamin -la violencia fundadora se vuelve conservadora- y Bourdieu -la ortodoxia se vela como doxa-. Aquí radica la fuerza de las normas jurídicas.

\subsection{La vida del otro -quizá del otro derecho-}

Como se acabó de ver, Bourdieu (2000) concede un espacio a las relaciones entre lo normal y lo patológico para el derecho, en cuanto concibe a éste como "instrumento de normalización por excelencia" (p. 213). Además, es también este autor el que fija la fuerza del derecho en el carácter doble que naturaliza unas normas inventadas, renovadas constantemente; en otras palabras, es gracias a que el derecho vuelve universal unos intereses particulares, que éste adquiere su poder. Por eso para Bourdieu (2000), la fuerza del derecho se produce a través del "efecto de universalización, que podríamos llamar también efecto de normalización" (p. 210); es decir, el derecho funciona debido a que hace pasar como normal aquello que no es sino "inventado", una forma más de nombrar.

Este proceso de normalización que Bourdieu considera junto a "lo normal y lo patológico", resulta importante en cuanto permite conceptualizar al derecho retomando la obra de 
Georges Canguilhem -maestro tanto de Bourdieu como de Foucault-, Lo normal y lo patológico. Por lo mismo, se podría decir que la batalla de la que habla Bourdieu, por el monopolio a decir qué es derecho, podría rebautizarse como la batalla por lo normal, cuando justamente lo que se enfrenta entre las normas son múltiples concepciones que se tienen sobre qué es normal. Éstas resultan ser imágenes en Bourdieu, visiones y divisiones; muy similar se encuentra en Canguilhem, cuando asegura que "nuestra imagen del mundo es siempre también una tabla de valores" (Canguilhem, 1971, p. 136). La imagen del mundo, es decir nombrar como se mostró con Bourdieu y el nomos, el derecho a decir derecho-, es siempre una tabla de valores: se clasifica qué es normal y qué se desea para la vida, en forma de prescripción. El mismo Canguilhem (1971) lo dice con detalle:

Si bien es cierto que el cuerpo humano es en cierto sentido un producto de la actividad social, no es absurdo sin embargo suponer que la constancia de determinados rasgos, revelados por un valor promedio, depende de la fidelidad consciente o inconsciente a ciertas normas de vida. (...) Un rasgo humano no sería normal porque fuese frecuente, sino a la inversa: sería frecuente por ser normal, es decir normativo en un género de vida dado (p. 120).

Una norma no refleja lo normal de una sociedad, sino que considera normal aquello que es antes nombrado, y por ende normativo, es decir, la palabra entendida como dispositivo hegemónico, (re)produciendo lo normal. Así, el cuerpo humano, antes que cualquier cosa fundamental o natural, es un producto de la actividad social. No por otra razón, cualquier rasgo constante entre la vida, lo normal para una población, no puede ser otra cosa que un producto normativo. Las normas no describen la realidad y sí prescriben un mundo, una vida, una muerte, un pasado y un futuro deseado, lo que permite corregir aquello que no se da como "debe ser".

Por otro lado, no es suficiente demostrar que lo normal se produce y es artificial. Es necesario revelar su proceso doble, como con la fuerza del derecho en Bourdieu y la violencia de Benjamin; es decir, aunque "la ortografía, la ortodoxia, [y] la ortopedia son conceptos normativos" (Canguilhem, 1971, p. 191), se figuran como normales, naturales y eternos. Lo contingente y azaroso se vuelve tan universal como normal:
Lo anormal como a-normal es posterior a la definición de lo normal. Sin embargo, la anterioridad histórica de lo anormal futuro es la que suscita una intención normativa. Lo normal es el efecto obtenido por la ejecución del proyecto normativo, es la norma exhibida en el hecho. Desde el punto de vista fáctico, existe pues entre lo normal y lo anormal una relación de exclusión. Pero esta negación está subordinada a la operación de negación, a la corrección requerida por la anormalidad. Por lo tanto, no hay nada paradójico en decir que lo anormal, lógicamente secundario es existencialmente primitivo (Canguilhem, 1971, p. 191).

Se percibe claramente el carácter doble del derecho entre la norma y lo normal, cuando lo anormal secundario se vuelve primitivo, en cuanto suscita que lo primario normal sea secundario en la corrección. Nuevamente se muestra lo que Walter Benjamin señaló como desechable del derecho, convierte lo artificial en natural, únicamente porque lo fundamental será luego desechado.

Este movimiento doble del derecho se da justamente por la tensión discursiva, por la "gramática de la guerra" (Valencia, 1987) que organiza qué es y no es derecho; es decir en el enfrentamiento por nombrar la normalidad. Es la dinámica hegemónica la que siempre trata de organizar la vida, como se vio con los anteriores autores y como lo expone Canguilhem (1971):

Cuando se habla de vida promedio, para aludir a su progreso creciente, se le relaciona con la acción que el hombre, considerado colectivamente, ejerce sobre sí misma (...) la muerte como un fenómeno social, estimando que la edad en la que ésta se produce es en gran parte el resultado de las condiciones de trabajo e higiene, de la atención a la fatiga y a las enfermedades (...) Todo sucede como si una sociedad tuviese "la mortalidad que le conviene", puesto que la cantidad de muertos y su distribución en las diferentes edades expresan la importancia que una sociedad da o no da a la prolongación de la vida. (...) finalmente, en ese número abstracto que es la duración promedio de la vida humana, está expresado un juicio de valor (p. 121). 
Estos cálculos y distribuciones, como las imágenes y el nomos en Bourdieu, son tablas de valores con una (di)visión de la vida: como la violencia para Walter Benjamin, se organiza qué es derecho y qué no, qué es normal y qué patológico para una comunidad que se proyecta

sobre el pasado y el futuro. Se calcula con la vida y la muerte de una población. La natalidad y la mortalidad se vuelven fenómenos sociales a disponer entre normas de higiene y trabajo, atendiendo a la fatiga y las enfermedades con la intención de gestionar los comportamientos individuales en una sociedad, construyendo la normalidad en el contexto de la economía y la política.

\section{Y DESPUÉS DE TODO, ¿QUÉ ES DERECHO PÚBLICO?}

\subsection{De "no matar" a las formas-de-vida}

La relación entre el derecho, la vida y la muerte, el pasado y el futuro, se ha visto a lo largo de este artículo. Para Walter Benjamin (1991), la capacidad jurídica de gestionar la vida y la muerte, "alcanza al derecho en su origen mismo" (p. 31). Bourdieu (2000), a su vez, sostiene que el campo donde se compite por el monopolio a nombrar el derecho, no es diferente a la batalla por universalizar un estilo propio de vida. Finalmente, en el anterior apartado con Canguilhem (1971), se expuso cómo el promedio de vida, los cálculos con la población, el examen de la mortalidad y la natalidad en una sociedad, se vinculan estrechamente con los juicios de valor que una sociedad posee y produce con sus normas. Así, podría afirmarse que el derecho se relaciona con las formas en que se gestiona la vida en una sociedad. Esto nos permite pensar en Diego López (2011), cuando afirma que "el derecho constitucional de los derechos fundamentales, debe tener pues, como preocupación central la vida” (XXVI). Pero, ¿qué es la vida?

Canguilhem (1971) asegura que la vida humana no puede limitarse a una vida vegetativa. En el derecho, la vida tampoco se agota en unos signos vitales; es decir, el derecho a la vida no es simplemente una mera existencia, sino la experiencia de ciertas normas que se consideran normales; la vida no se basta con solo vivir o respirar, como tampoco es vida un corazón latiendo o lo contrario a la muerte. Y como la vida no puede ser simplemente vivir, la vida resulta siempre doble, como se vio con las normas y lo normal, la violencia y la fuerza del derecho. No diferente, Giorgio Agamben (2001) recuerda, para exponer el ejercicio del biopoder ${ }^{3}$, cómo se concebía la vida en la Antigua Grecia:

Los griegos no disponían de un término único para expresar lo que nosotros queremos decir con la palabra vida. Se servían de dos términos semántica y morfológicamente distintos: zoé; que expresaba el simple hecho de vivir común a todos los vivientes (animales, hombres o dioses) y bios, que significaba la forma o manera de vivir propia de un individuo o un grupo (p. 13).

Entonces la vida para el derecho es el cumplimiento de una prescripción: una vida que, si no se desarrolla bajo protocolos tan concretos como determinados, no puede considerarse vida.

Pero si cualquier vida no es de derecho, ¿qué es el derecho a la vida? Afirma Giorgio Agamben (2001) en el texto "Derecho de muerte y poder sobre la vida", que "la vida aparece originariamente en el derecho tan solo como la contrapartida de un poder que amenaza con la muerte" (p. 14). Cuando la vida se limita a ser lo contrario de la muerte, el derecho no puede sino gestionar la muerte, "hacer morir o dejar vivir" (Foucault, 1977); y entonces el Estado puede disponer de la pena de muerte o prohibir el homicidio. Nada más. Con el paso del tiempo se transforma, del derecho que hace matar o deja vivir, se ha pasado al derecho que hace vivir, que gestiona la vida (Foucault, 1977).

\footnotetext{
3 En este trabajo se tomará la noción de biopolítica utilizada por Beatriz Preciado, cuando le compara con la sexualidad en el Manifiesto contra-sexual. Según este texto, "Foucault identificó cuatro dispositivos que nos permiten comprender la sexualidad como un producto de tecnologías positivas y productivas" (2002, p. 71). Así, cuando uno se dirige al texto de La historia de la sexualidad de Foucault (1977), denominado por Preciado como "la historia del biopoder", se encuentra con que la biopolítica es "un poder que se ejerce positivamente sobre la vida, que procura administrarla, aumentarla, multiplicarla, ejercer sobre ella controles precisos y regulaciones generales" (p. 98). No de otra forma se adopta la categoría de biopolítica en esta investigación, un poder positivo que gestiona la vida de una forma específica, para una población. Efectivamente, para concebir el biopoder, es necesario entender la vida.
} 
Contrario al aspecto negativo del "no matar", cuando se concibe la vida desde el derecho moderno, se dispone de un poder que se ejerce positivamente sobre los individuos (como con el ESD o los DESC). No se choca, no se reprime ni se mata, por el contrario se gestiona, se aumenta, se incita y se administra; como se mostró con las normas y los nombres, se distribuye la vida y se organiza el mundo en una imagen de valores. Entonces se desea como valor aquello que resulta acorde a la economía, un reglamento (como en la Casa de jóvenes delincuentes) dedicado al trabajo, la salud y la buena alimentación, contrario a la destrucción de los cuerpos o la violencia que arranca cabezas, brazos y piernas (como Damiens). Canguilhem (1971) lo expone claramente:

Deseado como valores es "la vida, una larga vida, la capacidad de reproducción, la capacidad de trabajo físico, la fuerza, la resistencia a la fatiga, la ausencia de dolor, un estado en el cual se note lo menos posible al cuerpo fuera del gozoso sentimiento de existencia" (p. 88).

Como se expuso, la vida cuando es bios no puede limitarse a una mera existencia; es necesario cumplir con cierta prescripción. Así, el derecho acoge la vida como bios, una forma-de-vida, donde la dignidad no puede faltar. La vida para el ESD, cuando se convierte en bios, necesita de salud, educación y trabajo, entre otros derechos como la vivienda; se trata de un programa donde es deseado como valor el trabajo físico, la resistencia a la fatiga, la ausencia de dolor y, en fin, una larga vida. Entonces el derecho a la vida, antes que hacer morir o dejar vivir, produce unas condiciones necesarias para desarrollar y promocionar una forma-de-vida deseada. Antes que un problema con zoé, se trata de gestionar bios, la vida para el derecho.

\section{2. ¿Qué es un derecho (dis)positivo?}

La vida resulta indispensable para el sistema jurídico en Colombia. No obstante, su desarrollo no se limita a penalizar cualquier homicidio injusto, cual mandamiento: no matarás. La vida en el ESD, al conectarse con la dignidad humana, es principio y valor constitucional; es decir que son necesarias las condiciones que le desarrollan plenamente junto a una justicia material, no solo sin obstáculos, sino con fuerza y promoción.

Es necesario recordar que con el ESD y los DESC, el derecho a la vida no se limita a un concepto negativo donde nadie puede matar a nadie injustamente, o donde el Estado debe limitar su actuar ante la vida de los ciudadanos. Por el contrario, para la Carta Superior de Colombia, el derecho a la vida es más un concepto positivo que promociona condiciones óptimas para su desarrollo. Tal cual se puede concebir con la sentencia T-622 de 2016, para el Estado de Colombia la vida es, antes que una pena o unos signos vitales, "la garantía de unas condiciones mínimas -o puntos de partida esenciales- que permitan el desarrollo de una vida digna, plena en el ejercicio de derechos y en condiciones de bienestar para todos los colombianos".

Efectivamente, para que el derecho a la vida de cada individuo en Colombia pueda desarrollarse plenamente, es necesario tener salud y trabajo, educación y alimentación, un mínimo vital y las necesidades básicas satisfechas, principios fundamentales para el ESD. El derecho a la vida es doble, obliga a no matar, pero también y aún más crucial, obliga a construir espacios que le promocionen bajo el concepto de la dignidad humana.

Esta distinción entre libertades negativas y derechos positivos, para el derecho a la vida, resulta importante en cuanto sólo así podrá concebirse qué entendemos en esta investigación por Derecho Público; como se dijo con Valencia (1987), un dispositivo. O mejor dicho, un proceso de producción -aparato positivo- que, antes que cualquier represión, activa a la sociedad y al Estado como los derechos (dis)positivos consignados en los DESC. Es entonces como, teóricamente, pueden relacionarse los derechos prestacionales, también denominados positivos, con aquello que Foucault denomina dispositivo y Beatriz Preciado (2002) retoma en El manifiesto contra-sexual:

Para Foucault, una técnica es un dispositivo complejo de poder y de saber que integra los instrumentos y los textos, los discursos y los regímenes del cuerpo, las leyes y las reglas para la maximización de la vida, los placeres del cuerpo y la regulación de los enunciados de verdad (p. 124).

Reglas para distribuir la vida, placeres del cuerpo y regulación de los enunciados de verdad, saber y 
poder es para Foucault un dispositivo. No se trata de prohibiciones ni represión, sino de administrar los cuerpos, nombrarlos y dividirlos: se organiza el mundo con la visión del derecho. En el mismo texto de Preciado (2002) es posible leer una relación entre los dispositivos y el actuar (dis)positivo que se analiza a través del ESD y los DESC, la distribución de la vida y la muerte, la di-visión del derecho:

(...) no son los efectos de las prohibiciones represivas que obstaculizarían el pleno desarrollo de nuestros deseos más íntimos, sino el resultado de un conjunto de tecnologías productivas (y no simplemente represivas). (...) no es, pues, la prohibición de determinadas prácticas, sino la producción de diferentes deseos y placeres que parecen derivar de predisposiciones naturales (...) no son un mecanismo represivo, sino estructuras reproductoras, así como técnicas de deseo y de saber que generan las diferentes posiciones de sujeto de saber-placer (p. 125).

Las técnicas, las estrategias o las tecnologías son dispositivos porque, antes que reprimir o chocar o prohibir, logran incitar, producir y organizar. Por lo mismo el derecho puede ser considerado como un dispositivo; antes que encarcelar o sancionar, como puede (mal) pensarse con el derecho penal, lo que hace es marcar los cuerpos con nombres, dividir, disponer y organizar la vida a través de la dignidad humana.

Por lo demás, si se concibe al derecho como un dispositivo, resulta interesante saber que Agamben (2011) denomina así aquello que tiene la "capacidad de capturar, orientar, determinar, interpretar, moldear, controlar y asegurar los gestos, las conductas, las opiniones y los discursos de los seres vivos" (p. 257). Como lo diría Bourdieu, el derecho (como dispositivo) es un campo; es decir, un saber que sostiene diferentes estrategias y relaciones de fuerza, un espacio donde juega el poder y sus diferentes actores, tratando de nombrar la vida de una población, normalizarla, disponerla, moldearla y manipularla.

3.3. Vida: el derecho a la salud, los derechos sexuales y los derechos reproductivos
Entendiendo el derecho público como un dispositivo que administra la vida, resulta de vital importancia un derecho como la salud -como ocurre con la Carta Superior del 91 y su Artículo 49-. Efectivamente, cuando se conceptualiza la salud desde el derecho, no se hace otra cosa que tensionar la muerte y la vida junto al pasado y el futuro, el bien y el mal para una población.

Es de saber que desde el Siglo XVIII la salud ocupa un lugar privilegiado entre la vida; no por otra razón, propone Foucault (1999), debe entenderse la salud como problema económico:

Se esboza el proyecto de una tecnología de la población: estimaciones demográficas, cálculo de la pirámide de edades, cálculo de las diferentes esperanzas de vida, de las tasas de morbidez, estudio del papel que juegan entre sí el crecimiento de las riquezas y el de la población, incitaciones diversas al matrimonio y a la natalidad, desarrollo de la educación y de la formación profesional. En el interior de este conjunto de problemas el «cuerpo» cuerpo de los individuos y cuerpo de las poblaciones- aparece como portador de nuevas variables: (...) más o menos utilizables, más o menos susceptibles de inversiones rentables, dotados de mayores o menores probabilidades de supervivencia, de muerte o de enfermedad, más o menos capaces de aprendizaje eficaz (pp. 332 - 333).

Entre esta tecnología de la población, la natalidad y las tasas de morbidez, la familia y la procreación, la higiene, la alimentación y el trabajo, se incrusta también el campo de los derechos sexuales y los derechos reproductivos (desde ahora DSDR), donde se juega por nombrar correctamente lo normal para la reproducción y el deseo.

Se administra (se nombra) públicamente lo que está bien y mal, lo que es dañino para el cuerpo colectivo y lo que le potencia, destruye o re-fuerza. No en otra estrategia biopolítica debe entenderse el derecho a la salud, los DSDR, la vida y el papel de los médicos: "observar, corregir, mejorar el «cuerpo» social y mantenerlo en un estado permanente de salud" (Foucault, 1999, p. 338). Entonces el derecho a la vida -como la salud y los DSDR-, no es un problema sobre matar o no matar, como tampoco una cuestión individual; por el 
contrario, se trata de gestionar una forma-de-vida (junto a la dignidad), para una población.

Entonces, para comprender qué es el derecho a la salud -como los DSDR- en este trabajo, es necesario saber que para Foucault (1999), la medicina no es otra cosa que una estrategia biopolítica; es decir:

El cuerpo humano entra de nuevo en un mercado económico desde el momento en que es susceptible de salud o de enfermedad, de bienestar o de malestar, de alegría o de sufrimiento, en la medida en que es objeto de sensaciones, deseos (Foucault, 1999, p. 357).

Sí, el derecho a la salud y los DSDR, que no son indiferentes al derecho a la vida como dispositivo, son estrategias biopolíticas que se deslizan en un campo donde se debate cómo nombrar el derecho, lo normal y lo patológico. Un espacio de batalla donde se enfrentan diferentes conceptos sobre la vida, los cuales pujan a través de múltiples estrategias, por imponerse.

\subsection{Experiencia subjetiva o las manos del derecho}

La concepción del derecho como dispositivo, en términos foucaultianos, puede interpretarse de otra forma más práctica. Como lo plantea Preciado (2002) para el género, no basta con señalar que el derecho es un constructo dinámico, en cuanto necesariamente se reclama "la posibilidad de intervenir en esta construcción” (p. 76). Efectivamente, cuando se concibe al derecho como un dispositivo, se busca también la posibilidad de intervenir en su proceso. Es entonces cuando podríamos afirmar que el derecho se convierte en una experiencia subjetiva y cada persona participa en su producción, jugando en el campo de las normas que nombran lo normal para una vida colectiva, por el pasado y el futuro de esa misma sociedad; el derecho se hace así un campo para incitar, producir y desviar múltiples posturas normativas, hacerlas chocar e introducir resistencias.

Manipular el campo jurídico, desmontarlo y remontarlo cuantas veces sea necesario e intervenir en su construcción, es la forma en que este trabajo concibe el derecho. En otras palabras, asegurar que el derecho es una experiencia subjetiva, es concebir que las normas jurídicas no son fórmulas abstractas ni ideas interiores en la profundidad de cada individuo. No se trata de un adentro que reflexiona sobre sí mismo ni de un afuera tan lejano descarnado- como ajeno a las personas; sino un campo con reglas propias donde se deslizan actores que le utilizan según sus intereses, como una caja de herramientas.

Así, Deleuze y Guattari (1985) recuerdan en el Anti-Edipo lo siguiente:

Marx decía: el mérito de Lutero radica en haber determinado la esencia de la religión ya no del lado del objeto, sino como religiosidad interior; el mérito de Adam Smith y de Ricardo radica en haber determinado la esencia o la naturaleza de la riqueza ya no como naturaleza objetiva, sino como esencia subjetiva abstracta y desterritorializada, actividad de producción en general (p. 278).

Freud, para Deleuze y Guattari (1985), concebía la sexualidad como una experiencia subjetiva, en cuanto el deseo depende de unas prácticas individuales y no de un objeto o la naturaleza; se trata de un "campo" donde se despliegan diversas estrategias, no una "cosa"; no es una fórmula abstracta ajena a las personas, ni algo innato en la profundidad interior de cada individuo. Es lo contrario, un espacio donde cada sujeto participa y transforma la historia -condiciones reales de existencia, según Marx (1974)- donde desarrolla su vida. Igual, la libido para Deleuze y Guattari (1985) no es una fórmula biológica ajena al trabajo, sino el proceso que cada sujeto experimenta, en la vida, con su cuerpo.

Igual que con la sexualidad en Freud, el derecho se toma en esta investigación como una experiencia subjetiva, donde cada persona puede intervenir en su construcción de formas diferentes, participando de la "gramática de la guerra" (Valencia, 1987) contra otros actores. Esta concepción no resulta diferente al campo jurídico que propone Ewick y Silbey (2001), con múltiples resistencias que chocan ante diversas conciencias jurídicas.

El derecho como experiencia subjetiva no puede entenderse como una idea al interior de cada persona o como un concepto dentro de los individuos, sino como una estrategia que reconoce la pluralidad jurídica, donde cada sujeto interesado 
participa en la batalla por nombrar qué es la vida. Esta postura no es diferente a la concepción del derecho como dispositivo, un campo que produce y tiene sus propias reglas, en cuanto la experiencia subjetiva despliega diferentes conciencias jurídicas, que pujan por modificar, reconstruir y tensionar qué se entiende por derecho, según los intereses puestos en juego.

Para cerrar, y retomando la pluralidad jurídica que caracteriza al derecho, consideramos que el derecho público es un espacio, donde intervienen diferentes actores y múltiples estrategias, enfrentándose por el monopolio de nombrar el derecho a la vida. Este combate, cual "gramática de la guerra" (Valencia, 1987), se desarrolla sin quemar, violar, matar o injuriar a una población; sino a través de su nomalización, usando cartas que organizan, distribuyen, dividen, calculan y gestionan los comportamientos, las prácticas, los pensamientos y los sentimientos colectivos. No basta con exponer la pluralidad jurídica, es necesario registrar los conflictos y crear los mapas de combate y los planos de campaña. Además, es de resaltar que estos mapas distribuyen el mundo con sus (di)visiones, nombres que normalizan con un discurso hegemónico, algunos intereses particulares, experiencias subjetivas.

\section{CONCLUSIONES}

En esta investigación se ha tomado al derecho como una experiencia subjetiva. Esta postura hace que cada persona, siempre que quiera y crea, puede intervenir en su construcción. Por lo mismo, no se trata de una cosa estática como una piedra, sino de un campo donde diferentes actores despliegan estrategias para intervenir en su creación, su construcción.. Así, el derecho se hace dinámico, inacabado, estratégico, posicional y relacional. Son las mismas manos que trabajan y transforman la naturaleza, las que construyen y reconstruyen las normas jurídicas, que con el tiempo se hacen normales para una población. No de forma diferente puede administrarse la vida y calcular con los cuerpos de una sociedad, gestionando a los individuos en sus comportamientos, deseos, nombres y (di)visiones. No por otra razón, también, se le ha denominado a lo largo de este artículo al derecho como "gramática de la guerra", donde se combate por imponer una imagen de la vida, donde se refleja también una escala de valores.
La relación del derecho con la vida $-\mathrm{y}$ la muertees bastante estrecha. Por lo demás, ni para el derecho ni para esta investigación, como tampoco para los derechos sexuales y derechos reproductivos, la vida se limita a unos signos vitales o un corazón palpitando; por el contrario, la vida como concepto jurídico, siempre trata de una forma-de-vida a gestionar, junto a la dignidad humana. No basta con la mera existencia para el derecho a la vida, por lo que es necesario gozar de salud y experimentar los DSDR. Por lo mismo es que el derecho, sin excluir la experiencia subjetiva, se concibe en este artículo como un dispositivo, en términos foucaultianos, incluyendo a los DESC y al ESD.

En fin, el derecho como experiencia subjetiva es un proceso con tres movimientos: 1) se evidencia que el derecho es múltiple, no se trata de una cosa estática ni un objeto inamovible fuera de la sociedad; el derecho es plural, como las conciencias jurídicas y sus resistencias; 2) como la pluralidad no basta, deben graficarse los mapas de cómo las diferentes posiciones jurídicas entran en conflicto; así se crean los planos de campaña; 3) la victoria transitoria de una carta de batalla, ordena el mundo, lo distribuye, hace una di-visión sobre qué es derecho y qué no, forjando una violencia cuando lo nombrado se hace normal.

\section{REFERENCIAS BIBLIOGRÁFICAS}

I. Agamben, G. (2001). Medios sin fin. Valencia, España: Pre-textos.

II. Agamben, G. (2011). ¿Qué es un dispositivo? Sociológica, 73, 249 - 264.

III. Arango, R. (2016). Realizando los derechos. Su filosofía y práctica en América Latina. Querétaro, México: Instituto de Estudios Constitucionales.

IV. Ariza, R. (2015). El pluralismo jurídico en América Latina y la nueva fase del colonialismo jurídico en los estados constitucionales. Revista insurgencia, 1, 165 - 194.

V. Benjamin, W. (1991). Para una crítica de la violencia. España: Taurus S.A.

VI. Borrero, C. (2006). Derechos humanos: ideas y dilemas para animar su comprensión. Bogotá, Colombia: CINEP, Centro de investigaciones y educación popular. 
VII. Bourdieu, P. (1991). Los juristas, guardianes de la hipocresía colectiva. En F. Chazel y J. Commaile. (Eds.), Normas jurídicas y regulación social. Paris, Francia.

VIII. Bourdieu, P. (2000). Elementos para una sociología del campo jurídico. En La fuerza del derecho (153 - 220). Bogotá, Colombia: Siglo del hombre editores.

IX. Canguilhem, G. (1971). Lo normal y lo patológico. Buenos Aires, Argentina: Siglo XXI editores.

X. Constitución Política de Colombia. [C.P.]. 1991.

XI. Deleuze, G. y Guattari, F. (1985). AntiEdipo. Capitalismo y esquizofrenia. Barcelona, España: Ediciones Paidós.

XII. Ewick, P., y Silbey, S. (2001). Conformismo, oposición y resistencia: un estudio sobre la conciencia jurídica. En M. García. (Ed.), Sociología jurídica: teoría y sociología del derecho en los Estados Unidos (pp. 267 - 289). Bogotá: Universidad Nacional.

XIII. Foucault, M. (1975). Vigilar y castigar. Buenos Aires: Siglo XXI.
XIV. Foucault, M. (1977). Historia de la sexualidad I: la voluntad de saber. México: Gallimard.

XV. Foucault, M. (1999). Estrategias de poder. Barcelona, España: Paidós.

XVI. López, D. (2011). El derecho de los jueces. Bogotá, Colombia: Legis.

XVII. López-Daza, G. (2017). Nuevos paradigmas del derecho constitucional colombiano. Medellín: Biblioteca jurídica Diké.

XVIII. Marx, C. (1974). La ideología alemana. Barcelona, España: Ediciones Grijalbo.

XIX. Preciado, B. (2002). Manifiesto contrasexual. Madrid, España: Editorial Opera Prima.

XX. Valencia, H. (1987). Cartas de batalla. Bogotá, Colombia: Panamericana.

\section{REFERENCIAS JURISPRUDENCIALES}

XXI. CConst, T-406/1992, M.P. C. Angarita.

XXII. CConst, C-113/1993, M.P. A. Martínez.

XXIII. CConst, C-131/1993, M.P. A. Martínez.

XXIV. CConst, T-622/2016, M.P. J. Palacio 